\title{
Positron Annihilation Studies of the Subsurface Zone in Aluminium Alloys
}

\author{
E. DRYZEK ${ }^{a, *}$ AND J. DRYZEK ${ }^{a, b}$ \\ ${ }^{a}$ Institute of Nuclear Physics, Polish Academy of Sciences \\ Radzikowskiego 152, 31-342 Kraków, Poland \\ ${ }^{b}$ University of Zielona Góra, Institute of Physics \\ Prof. Szafrana 4a, 65-516 Zielona Góra, Poland
}

\begin{abstract}
The paper presents positron lifetime studies of the subsurface region of the aluminium cast AK64 alloy containing silicon as a main alloying element after sliding against stainless steel in the pin-on-disc tester. The subsurface zone of the depth exceeding $150 \mu \mathrm{m}$ has been detected. The scanning electron microscopy revealed only the plastically deformed region occurring at the depth up to $c a .50 \mu \mathrm{m}$ and cracks at the depth less than $30 \mu \mathrm{m}$. The comparison with the results obtained for the AK12 alloy containing almost a twice higher amount of silicon demonstrates the influence of the hard silicon rich particles on the total depth of the subsurface zone. A higher amount of hard particle prevents to some extend the propagation of defects inside the material.
\end{abstract}

PACS numbers: $78.70 . \mathrm{Bj}$

\section{Introduction}

The relative motion of one solid surface over another is an important aspect of the functioning of different mechanisms. It is always accompanied by wear, i.e. damage of one or both surfaces involving progressing loss of material. The sliding contact induces also changes in the microstructure and properties of the subsurface which can affect the wear process $[1,2]$. The arisen subsurface can be examined using variety of analytical techniques such as scanning electron microscopy (SEM), transmission electron microscopy (TEM), X-ray diffraction, microhardness measurements. The positron annihilation spectroscopy has also turned out to be a useful tool of the subsurface region examination since the surface modification induces plastic deformation connected with the creation of crystal lattice defects which can be detected using this method [3, 4]. Although the dislocation network

*corresponding author; e-mail: Ewa.Dryzek@ifj.edu.pl 
can be studied directly by TEM, in general, vacancies and small vacancy clusters are not detectable by TEM. Similarly, the microhardness profile measured in the subsurface region allows obtaining information on work hardening connected to a large extent with the increase in dislocation density. However, dislocation movement during plastic deformation generates a large amount of point defects. Positrons are very sensitive and unique probes for point defects such as vacancies and vacancy clusters, and also dislocations. This is due to the high trapping rate of thermalized positrons especially in point defects, which is proportional to the defect concentration [5].

In the case of dry sliding a great amount of points defects like vacancies associated with dislocations (in aluminium) [6] or vacancy clusters (in copper) [7] was found below the worn surface using this method. Their concentration decreased with depth and reached the bulk value at a depth of hundreds of micrometers. The limited implantation range of positron from ${ }^{22} \mathrm{Na}$ gives the opportunity to determine the total range of the crystal lattice changes induced by friction and wear including the region deformed elastically. In spite of the complexity of the alloy microstructure and wear induced deformation of the subsurface region, positron annihilation allowed one to determine the total range of the subsurface zone also in aluminium wrought alloys $[8,9]$.

The paper presents studies of the subsurface region originated in dry sliding of aluminium cast alloy AK64. It is a continuation of our interest in aluminium cast alloys rich in silicon whose microstructure consists in the presence of hard silicon particles distributed in the aluminium matrix. The silicon content in AK64 alloy, however, is lower than in the near-eutectic AK12 alloy studied previously [10]. The comparison of the obtained results may shed light on influence of hard particles on the defect profiles in the subsurface region. To this end the positron lifetime spectroscopy was applied. The subsurface has been also examined using scanning electron microscopy.

\section{The experimental procedure}

The samples were machined from the commercial aluminium cast alloy AK64 (with the following composition: Si 6.18 wt.\%, Cu 3.43 wt.\%, Mg 0.49 wt.\%, Mn 0.35 wt.\%, Ni 0.5 wt.\%, impurirties: Zn 0.08 wt.\%, Fe 0.23 wt.\%, Ti 0.06 wt.\%, Ni 0.008 wt. $\%$, Sn 0.05 wt. $\%$, Pb 0.008 wt.\%, Cr 0.01 wt. $\%$, Al balance) in the form of cylinders $15 \mathrm{~mm}$ high and $10 \mathrm{~mm}$ in diameter. The dry sliding tests were carried out in the pin-on disk apparatus in air at room temperature. The cylinder was a pin whose flat end surface was sliding against a disk of diameter $50 \mathrm{~mm}$ made from the martensitic steel (SW18 hardness about 670 HV0.1). The sliding velocity $50 \mathrm{~mm} / \mathrm{s}$ was maintained during the test. The tests were carried out with the load of $106 \mathrm{~N}$ for different sliding distances.

The positron lifetime spectra were measured using the conventional fastfast spectrometer with $\mathrm{BaF}_{2}$ scintillators. The time resolution of the system was 
$250 \mathrm{ps}$ (FWHM). The positron source ${ }^{22} \mathrm{Na}$ (activity $38 \mu \mathrm{Ci}$ ) in $7 \mu \mathrm{m}$ thick kapton foil was sandwiched between the basal surfaces of two cylinders treated by the same procedure in a pin-on-disc tester and the positron lifetime spectrum was measured. All obtained spectra containing about $2 \times 10^{6}$ counts were deconvoluted using the LT code subtracting the background and the source component [11]. Positrons emitted from the ${ }^{22} \mathrm{Na}$ source have a sufficient energy $\left(E_{\max }=544 \mathrm{keV}\right)$ to penetrate a certain depth of the specimen, i.e. about $94.2 \mu \mathrm{m}$, which is the inverse value of the linear absorption coefficient in aluminium [12]. The measured positron lifetime depth profile is a convolution of the positron implantation profile and the actual positron lifetime depth profile [13]. At this stage it is difficult to deconvolute obtained experimental dependences. However, the total range and the main features of the positron lifetime changes with depth can be relatively well established.

The positron lifetime dependence on the depth was obtained by sequenced measurement of the positron lifetime spectrum and after that removing of a $30 \mu \mathrm{m}$ thick layer from the worn basal surfaces of two cylindrical samples. The layers were removed by grinding using $\mathrm{SiC}$ pastes on thick iron plate. The reduction of the specimen thickness was checked with $\pm 5 \mu \mathrm{m}$ accuracy using a micrometer screw. The removed layer thickness is referred to as the depth below the surface exposed to sliding. Grinding may induce additional defects into subsurface layer of the samples but the contribution to the positron lifetime spectrum coming from these defects is small comparing to sliding induced defects which is connected with much lower values of the normal force pressing the sample against the counterface. This contribution is more or less the same for all the measurements and thus changes in the positron lifetime spectra can be attributed to sliding.

The SEM micrographs were obtained using an ISN-5400 Jeol scanning electron microscope. After sliding in the pin-on-disc tester, the sample for SEM investigation was cut normally to the worn surface using a low speed diamond saw and surface of the section was polished.

\section{Results and discussion}

The cross-sectional scanning electron micrographs for AK64 samples whose surfaces were sliding at distance of $18 \mathrm{~m}$ with the load of $108 \mathrm{~N}$ are given in Fig. 1a and $\mathrm{b}$. There can be seen particles of precipitates rich in Si which are distorted and reoriented toward the direction of sliding marking deformation of the subsurface layer to the depth of $c a .50 \mu \mathrm{m}$ (Fig. 1a). Figure $1 \mathrm{~b}$ shows cracks in the region just beneath the worn surface. The cracks do not propagate deeper than 20-30 $\mu \mathrm{m}$ and are elongated parallel to the worn surface direction. The mixed layer is not visible in the pictures.

In all positron lifetime spectra measured for the AK64 alloy a single component was sufficient to obtain a satisfactory fit. Such single component spectra were already reported for the $\mathrm{Al}-\mathrm{Cu}-\mathrm{Mg}$ alloys [14]. This was interpreted as an outcome 

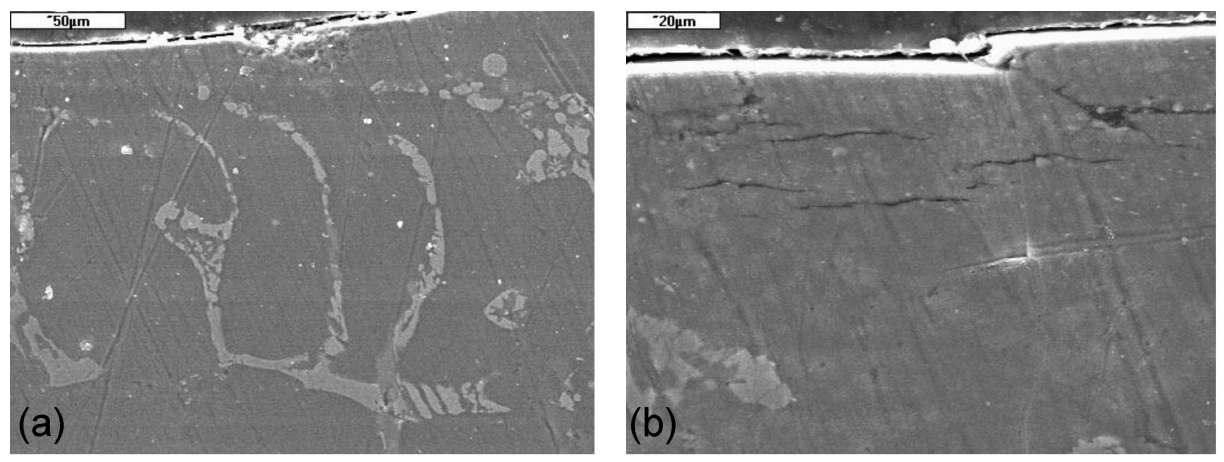

Fig. 1. SEM micrographs showing the subsurface features in the AK64 specimen wear tested at the load of $108 \mathrm{~N}$, sliding distance $18 \mathrm{~m}$ : (a) Si rich precipitates, (b) cracks.

of competitive trapping in different families of defects giving lifetimes too close to be isolated. In this case, both the microstructure connected with the presence of precipitates in the alloy and the plastic deformation of the subsurface contribute to variety of positron trapping sites. Positron bulk lifetime in silicon is well known and it is equal to $218 \mathrm{ps}$ [5]. However, this component cannot be extracted from the spectra because it is close to the measured values of positron lifetimes. Besides, the precipitates may contain atoms of other alloying elements and crystal lattice defect which influence the positron lifetime in precipitates. Thus, the evaluated from the spectra positron lifetime value can be treated as an average one, and it is presented in Fig. 2 as a function of depth for different sliding distances. Contents of silicon may influence the average bulk positron lifetime value in the alloy.

The positron lifetime obtained for the samples before sliding which will be referred to as the bulk value is equal to $213 \pm 1 \mathrm{ps}$. For the sliding distance of $6 \mathrm{~m}$, only the positron lifetime measured directly at the worn surface is higher than the bulk value. Thus, the increase in defect concentration and/or presence of defects giving a higher positron lifetime is limited to the $30 \mu \mathrm{m}$ thick or thinner layer. For the higher distances: $18 \mathrm{~m}$ and $54 \mathrm{~m}$ the lifetime values measured for the depth up to $90 \mu \mathrm{m}$ are very close to each other. Deeper, the positron lifetime for the longer distance of $54 \mathrm{~m}$ seems to be higher. After the steep decrease for the first $30 \mu \mathrm{m}$ further decrease is more or less linear. The total range of the subsurface zone can be estimated between $150 \mu \mathrm{m}$ and $200 \mu \mathrm{m}$ taking into account that it is difficult to find out if the risen value for the depth of $180 \mu \mathrm{m}$ is significant and may indicate a layer with e.g. a higher concentration of defects. The positron lifetime decrease with depth deviates from the exponential form.

An exponential relationship of positron lifetime on depth was obtained also for cast aluminium alloy AK12 with a higher content of Si (12-13.5 wt.\%) and the wrought aluminium alloy 2017A containing $\mathrm{Cu}$ and $\mathrm{Mg}$ [8]. Nevertheless, this dependence obtained for the wrought aluminium alloy $6061 \mathrm{~A}$ containing less than $1 \%$ of Si and Mg was linear [8]. Both these wrought alloys are characterized by lower 


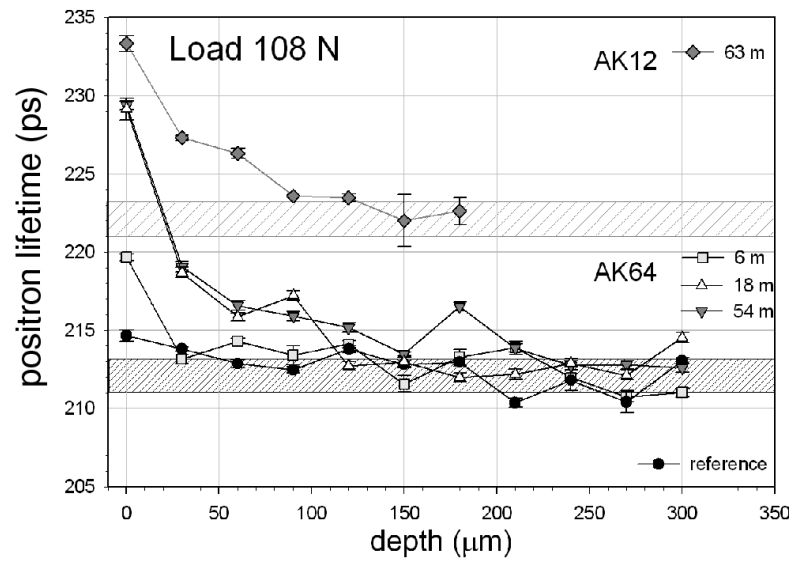

Fig. 2. The positron lifetime as a function of the depth measured for the specimens of the AK64 alloy which were treated in the sliding experiment for the distances of $6 \mathrm{~m}, 18 \mathrm{~m}$, and $54 \mathrm{~m}$. For comparison there is also depicted the positron lifetime as a function of depth for the AK12 alloy for sliding distance $63 \mathrm{~m}$. The shaded areas mark the bulk values of the positron lifetime for the AK12 alloy (upper) and for the AK64 alloy (lower).

content of alloying elements, different microstructure and hardening mechanisms than the aluminium-silicon cast alloys. For both alloys, the well-defined positron lifetime profile of the subsurface region arose already for a sliding distance of a few meters. For pure aluminium the positron lifetime after a clearly noticeable decrease reached at the depth of $200 \mu \mathrm{m}$ a plateau which extended up to $450 \mu \mathrm{m}$, i.e. much deeper than for the alloys studied, even after sliding against a graphite pin with a load of only $56 \mathrm{~N}[6,15]$. The large total range of the subsurface zone in that case resulted not only from shear stress but also from normal stress caused by the load.

Comparing the positron lifetime profiles for the AK64 alloy with those obtained previously for AK12 alloy [10] for similar distances one can notice the higher increase in the positron lifetime measured directly on the surface for the first alloy. It seems that a higher number of defects is created close to the surface in the $30 \mu \mathrm{m}$ thick layer. The total depth of the positron lifetime profile is also higher. It can be estimated at least $150 \mu \mathrm{m}$ whereas this depth for the AK12 alloy can be estimated at $120 \mu \mathrm{m}$. It confirms the conclusion drawn from the comparison of the positron lifetime profiles in AK12 alloy and AK12 alloy composite with $\mathrm{Al}_{2} \mathrm{O}_{3}$ particles that hard particles prevent dislocation movement inside the material [10]. However the difference in the total depth of the positron lifetime profile is lower than it would be expected taking into account almost a twice lower content of silicon in AK64 alloy in comparison with AK12 alloy.

As far as the work hardening of the subsurface region resulting from the sliding contact is concerned the relationship of strain as a function of depth below 
the worn surface was demonstrated to have an exponential character for steel [16], copper and copper alloys [17], $\mathrm{Al}-4.31 \mathrm{wt} . \% \mathrm{Cu}$ and $\mathrm{Al}-11.7 \mathrm{wt} . \% \mathrm{Si}$ alloys [1]. However, for high purity copper the linear change in flow stress below the surface was observed [18]. Therefore, it seems that in the case of the AK64 alloy the positron lifetime profile and what follows the defect concentration profile connected with the subsurface deformation has a similar character. However the total range of the subsurface region revealed by positron lifetime spectroscopy exceeds $150 \mu \mathrm{m}$, which is much more than the depth of microstructure features induced by sliding observed using SEM, which results from the fact that positron annihilation gave quantitative information on the total depth of the subsurface region including the zone deformed elastically.

\section{Conclusions}

The obtained results of the positron lifetime measurements of the subsurface region arisen in the AK12 alloy samples as a result of dry sliding against steel confirmed the conclusion that hard particles distributed in aluminium matrix prevent the propagation of defects inside the material. However the influence of the silicon concentration on the total depth of subsurface zone and the positron lifetime profile is not straightforward.

\section{Acknowledgment}

This work was supported by the State Committee for Scientific Research (Poland), project No. 620/E-77/SPB/COST/T-08/DWM 49/2004-2005.

\section{References}

[1] P.J. Blau, J. Mater. Sci. 19, 1957 (1984).

[2] C. Perrin, W.M. Rainforth, Wear 203-204, 171 (1997).

[3] J. Dryzek, E. Dryzek, T. Stegemann, B. Cleff, Tribol. Lett. 3, 269 (1997).

[4] W. Egger, G. Kögel, P. Sperr, W. Triftshäuser, J. Bär, S. Rödling , H.-J. Gudladt, Mater Sci. Eng. A 387-389, 317 (2004).

[5] R. Krause-Rehberg, H.S. Leipner, Positron Annihilation in Semiconductors: Defect Studies, Springer, Berlin 1999.

[6] J. Dryzek, E. Dryzek, Mater. Sci. Forum 445-446, 72 (2004).

[7] J. Dryzek, A. Polak, Tribol. Lett. 7, 57 (1999).

[8] E. Dryzek, J. Dryzek, Tribol. Int. 39, 669 (2006).

[9] E. Dryzek, J. Mater. Sci. 38, 3755 (2003).

[10] J. Dryzek, E. Dryzek, Wear 261, 549 (2006).

[11] J. Kansy, Nucl. Instrum. Methods Phys. Res. A 374, 235 (1996).

[12] J. Dryzek, Appl. Phys. A 81, 1099 (2005).

[13] J. Dryzek, Nukleonika 42, 95 (1997). 
[14] A. Somoza, A. Dupasquier, I.J. Polmear, P. Folegati, R. Ferragut, Phys. Rev. B 61, 14454 (2000).

[15] J. Dryzek, E. Dryzek, Tribol. Lett. 17, 147 (2004).

[16] W.M. Rainforth, R. Stevens, J. Nutting, Philos. Mag. A 66, 621 (1992).

[17] D.A. Rigney, M.G.S. Nylor, R. Divakar, L.K. Ives, Mater. Sci. Eng. 81, 409 (1986).

[18] D.A. Hughes, D.B. Dawson, J.S. Korellis, L.I. Weingarten, Wear 181-183, 458 (1995). 